\title{
USAHA-USAHA CHINA MENYEKAT PENJAJAHAN PERANCIS DI VIETNAM PASCA PERJANJIAN SAIGON 1874
}

\author{
Ku Boon Dar
}

\begin{abstract}
The Treaty of Saigon, signed on March 15, 1874, stated that Vietnam recognized the full sozereignty of France over Cochin China (South Vietnam). Although France returned Hanoi, the Vietnamese enperor was edgy and sought assistance from China. Consequently, both France and China claimed sovereignty over Vietnamese territory. China move to address the conflict in Vietnam generated polemics among the Chinese mandarin officers zoho sought to obtain a comprehensive resolution. However, a dispute arose among them and led to a different solution. This article attentpts to examine China's various approaches in this conflict and, secondly considers the extend to which it prevented France from disnupting the protectorate relationship that existed between China and Vietnam under the tributary system. By looking at the response of the Chinese government towards Vietnam's disputed sovereignty and its efforts to prevent French colonisation, this study help us to understand the relevance of the tributary system as a mechanism of Sino Vietnantese relations even though it had existed for centuries ago and was being challenged in that crucial era.
\end{abstract}

\section{Pengenalan}

Perjanjian Saigon 1874 yang ditandatangani pada 15 Mac dengan Vietnam tidak memberi kepuasan kepada Perancis lantaran hubungan antara Vietnam dengan China masih diteruskan kerana kedua-dua buah negara tersebut tidak mematuhi butiran perjanjian tersebut. Ini 
menyebabkan Perancis terdesak untuk mengukuhkan kekuasaan di Vietnam. Peluang tersebut terbuka dengan kekacauan politik dalaman di Vietnam yang tidak berkesudahan, memudahkan usaha-usaha penjajahan Perancis ke atas Vietnam lalu dimanfaatkan kesempatan tersebut menandatangani perjanjian-perjanjian lain dengan Vietnam. Sementara itu, China terpaksa mengusahakan pelbagai pendekatan untuk menyelamatkan Vietnam daripada terus diterjah oleh Perancis. Namun dalam usaha menangani konflik di Vietnam, berlaku polemik dalam kalangan para pembesarnya demi mencari satu resolusi yang tuntas. Justeru, terdapat beberapa cad angan yang disarankan oleh para pembesar tersebut dan pelbagai usaha telah dilakukan oleh China dalam usahanya menyekat penjajahan Perancis ke atas Vietnam sebelum meletuskan Perang China-Perancis 1884-1885. Ini kerana perbalahan yang timbul dalam kalangan pembesar China telah mencetuskan jalan penyelesaian yang berbeza. Sesetengahnya menyuarakan strategi rundingan dan persetiaan, manakala sesetengah pembesar yang lain pula lebih terarah kepada pendekatan ketenteraan untuk menyelesaikan konflik yang berlaku di Vietnam.

\section{Detik-Detik kepada Perjanjian Saigon 1874}

Pada tahun 1872, Jean Dupuis (1829-1912) seorang peniaga Perancis tiba di Kunming dari Wuhan. Ma Rulong, Gabenor China di Yunnan meminta beliau membekalkan senjata api kepada China bagi menghadapi Pemberontakan Muslim di Yunnan. Lalu Jean Dupuis memaklunikan rancangannya kepada Perancis kerana beliau berhasrat meneroka laluan baru tersebut menggunakan kapal perang Perancis dari Kunming dan keluar menyusuri hingga ke Teluk Tonking di Vietnam. Louis Adolphe Bonard (1805-1867), Menteri Jajahan dan Angkatan Tentera Perancis mengizinkan beliau "meminjam" Vietnam untuk pelayaran tersebut sambil menyarankan kepada Jean Dupuis meneroka laluan baru dari Sungai Merah ke Yunnan di China.'

Pada bulan Mac 1873, beliau berjaya menyerahkan senjata api kepada Gabenor Ma Rulong di Yunnan, lalu menggunakan kapal untuk mengangkat hasil bijih dari Manhao di Yunnan ke Tongking. ${ }^{2}$ Namun, aktiviti membekal senjata api kepada Yunnan dan usaha memperolehi hasil semulajadi dari Yunnan mendapat bantahan daripada penduduk Vietnam kerana Jean Dupre terpaksa melalui Sungai Merah. Pada 24 Mei 1873, beribu-ribu penduduk Tongking mengadakan mogok memprotes tindakan Jean Dupuis. Ini menyebabkan Nguyen Tri Phuong, gabenor Hanoi menyerahkan notis bantahan kepada Perancis dan melarang rombongan Jean Dupuis memasuki Sungai Merah. Namun, notis bantahan tersebut tidak diendah oleh Jean Dupuis sebaliknya dengan 
angkuh dan nada ugutan, beliau melontarkan kata-kata bahawa, "Aku akan bunuh sesiapa yang menentang rancangan aku".

Pertikaian tersebut menjadikan kawasan di sempadan ChinaVietnam dalam keadaan genting. Lantaran itu, sekali lagi Jean Dupuis dilarang oleh Vietnam daripada menjalankan sebarang aktiviti penjualan dan pembelian garam di Sungai Merah kerana Vietnam memonopoli aktiviti tersebut. ${ }^{4}$ Nanun, Perancis lebih licik mengambil kesempatan dan berselindung di sebalik keadaan kacau-bilau di Tonking lalu menghantar seramai 188 orang tentera Perancis yang diketuai oleh komander Marie Jospeh Francois Garnier (1839-1873) ke Tongking. ${ }^{5}$ Walaupun penyelesaian gagal dicapai, Francois Garnier telah mengisytiharkan Sungai Merah dibuka untuk perdagangan kepada pihak Barat. Tindakan ini seperti mana digambarkan oleh Morse sebagai tindakan dan usaha "good pretext and opportunity" yang dimanfaatkan oleh Gabenor Jeneral Cochinchina Laksamana Jules Dupre (1813-1881) untuk campur tangan di Vietnam.

Sesungguhnya, faktor ekonomi merupakan sebab utama Perancis campurtangan di Tonking. Mereka percaya bahawa Sungai Merah akan muncul sebagai laluan yang terpenting dalam kawasan barat China. Stephen $\mathrm{H}$. Roberts berpendapat bahawa:

The English [British] looked on the same water-way as a route whereby to
connect their China, Burma and India trade in one vast system. Between
1865 and 1889 . they [British] sent eleven exploring expeditions into the
China-Burma area planning to draw the west China trade to Rangoon or
Calcutta thus depriving Hanoi of the importance which France wanted for it.?

Selain itu, keghairahan Perancis menakluki Tonking juga disebabkan kebimbangan mereka terhadap usaha-usaha British yang berhasrat menjalinkan hubungan diplomasi dengan Yunnan. Lantaran itu, Perancis khuatir British yang telah menjajah Burma akan menebarkan jaringan kekuasaan mereka ke Vietnam. Natijahnya, Perancis menyegerakan misi penawanan mereka ke atas Tongking seperti mana menurut D. G. E. Hall bahawa pemilikian Delta Mekong (Vietnam) menjadi cabaran kepada Perancis untuk British yang telah menduduki Delta Irrawaddy (Burma) dalam perlumbaan untuk perdagangan dengan bahagian barat daya China. ${ }^{8}$ Ini sepertimana ditegaskan oleh Hu Sheng bahawa The French ambition was not the conversion of rich Vietnam into a French colony but also to use this new colony as a stepping stone to reach the Chinese provinces of Yunnan and Guangxi and the rest of Southwest China. ${ }^{9}$

Apabila Charles de Freycinet (1828-1892) menjawat sebagai Menteri Luar Perancis pada tahun 1876, beliau menyokong kuat usaha perluasan jajahan ekonomi bagi kepentingan Perancis. Ini kerana Perancis 
mulai pulih daripada kesan kekalahan mereka dalam Perang PrussiaPerancis ${ }^{10}$ dengan tertubuh Republik Ketiga. ${ }^{11}$ Kejatuhan Maharaja Napoleon III dan Perang Franco-Prussian menyebabkan para imperialis Perancis di Vietnam tidak mengharap sebarang sokongan dari Paris. Namun segala peluang yang ada tetap diambil dan pada hakikatnya mereka tidak menghentikan cita-cita mereka untuk menaw an Tonking dari Vietnam. ${ }^{12}$ Pada 20 November 1873, kubu Hanoi telah ditawan oleh para imperial Perancis. Namun pada 21 Disember, 1873, Pasukan Bendera Hitam, pimpinan Liu Yongfu berjaya membunuh Marie Joseph Francois Garnier lalu menyingkir tentera Perancis dari Hanoi. Walau begitu, berita kekalahan itu tidak merencat tindakan pencerobohan Perancis di utara Vietnam. Sebaliknya Inspector of Native Affairs di Saigon, Philastre telah diutuskan oleh Laksamana Marie Jean Dupre (1839-1873), Gabenor Jeneral Perancis di Saigon berunding dengan Vietnam bagi menyelesaikan pertelingkahan tersebut. ${ }^{13}$

Sementara itu, pemerintah Vietnam, Maharaja Tu Duc (1829-1883) begitu khuatir terhadap kematian Komander Marie Joseph Francois Garnier dalam pertempuran dengan Pasukan Bendera Hitam. Ini kerana pertempuran tersebut akan menyebabkan Perancis bertindak balas terhadap Vietnam. Maharaja Tu Duc berpendapat bahawa kejayaan Pasukan Bendera Hitam membunuh Francois Garnier adalah melalui tipu-helah dengan berpura-pura kalah sebelum bertindak semula dengan serangan hendap ke atas tentera Perancis di Cau Giay. Baginda percaya sekiranya Vietnam yang didokong oleh Pasukan Bendera Hitam tersebut berperang secara terbuka dengan tentera Perancis buat kesekian kalinya, tentera Vietnam tentu akan mengalami kekalahan. Ini kerana Pasukan Bendera Hitam yang telah ditubuhkan oleh Liu Yongfu setelah Wu Yazhong, pemimpin gerakan tani tersebut ditumpaskan oleh China pada tahun 1869 adalah terdiri daripada bekas ahli gerakan tani dari Guangxi dan mereka juga terpaksa berlindung di Vietnam. ${ }^{14}$

Oleh itu, misi Philastre berjaya meyakinkan Vietnam apabila mereka bersetuju menandatangani Perjanjian Saigon 1874 pada 15 Mac 1874 dan disahkan pada 1 Ogos 1874 . Perjanjian ini antara lain menyebut bahawa pendudukan Perancis ke atas Cochinchina diakui oleh Maharaja Tu Duc, menerima seorang Residen Perancis di Hue serta membuka pelabuhan Qui Nhon, Tourane (Da Nang) dan Hanoi (Gia Dinh). Tiap-tiap pelabuhan ini telah ditempatkan seorang konsul Perancis. Selain itu, kapal Perancis diberi kebebasan belayar dan menjalankan aktiviti perdagangan melalui Sungai Merah hingga ke Yunnan. Perancis tidak lagi menuntut baki ganti rugi perang tahun 1862 dan akan membekalkan kapal-kapal perang serta senjata untuk menentang Pasukan Bendera Hitam. Raky at Perancis juga turut diberi kebebasan beragama di Vietnam pada ketika itu. ${ }^{15}$ 


\section{Kepentingan Perjanjian Saigon 1874}

Melalui perjanjian ini, kerajaan Perancis mengakui kemerdekaan dan kedaulatan Vietnam serta berjanji melindungi Vietnam daripada sebarang pencerobohan luar. Sebagai balasannya, Vietnam bersetuju menyerahkan hubungan dasar luar Cochinchina [Vietnam Selatan] kepada Perancis. Dengan lain perkataan, Vietnam telah memindahkan kuasa kedaulatan negara mereka kepada Perancis. ${ }^{16}$ Oleh itu, dengan termeterainya Perjanjian Saigon 1874, ia menimbulkan pelbagai reaksi di Perancis. Bagi para penyokong imperialis di Perancis, perjanjian ini merupakan kemenangan kepada mereka kerana pada pendapat mereka, Perancis berjaya mengalihkan kiblat ketuanan Vietnam daripada China kepada Perancis. ${ }^{17}$ Di samping itu, golongan penyokong imperialis juga berpendapat bahawa perjanjian tersebut merupakan sebuah perjanjian memberi hak petuanan (protection) kepada Perancis kerana Vietnam telah menjadi negeri naungan Perancis (protectorate state) walaupun tidak tercatat dalam perjanjian tersebut. ${ }^{18}$ Bagi pihak yang menentang idea imperialisme di Perancis pula, mereka juga menganggap bahawa Perjanjian Saigon 1874 ini merupakan kemenangan bagi mereka kerana perjanjian ini memperlihatkan tekad dan usaha Perancis untuk membebaskan Vietnam secara total daripada sebarang kuasa asing ke atas Vietnam termasuk China dan mengiktiraf kedaulatan Maharaja Vietnam. ${ }^{19}$

Manakala di pihak China, walaupun mereka menyedari akan kewujudan Perjanjian Saigon 1874, tetapi istana di Beijing terus menerima barang ufti dan istiadat mengadap daripada Vietnam seperti yang berlaku pada tahun 1876,1877 dan 1880 . Begitu juga pada tahun 4 Oktober 1880, utusan tributari Vietnam sekali lagi ke China. Lantaran itu, pada awalnya China melihat bahawa Perjanjian Saigon sebagai sebuah perjanjian yang tidak mengancam hak pertuanan China ke atas Vietnam. Sebaliknya China beranggapan bahawa hubungan China dengan negeri-negeri naungan termasuk Vietnam hanya memerlukan pengiktirafan dari negeri naungan itu sendiri. la tidak memerlukan pengiktirafan dari negara lain. Oleh itu, pada tahun 1875 dan 1880 contohnya, Maharaja Guangxu (1871-1904) terus menghantar angkatan tentera dari China yang diketuai oleh Feng Zicai (1818-1903) ke Vietnam untuk membantu menghapuskan pemberontakan yang dilakukan oleh Wang Zongyin di Ho Nam, utara Vietnam. ${ }^{20}$

Selain itu, Vietnam yang tidak memaklumkan kepada China tentang Perjanjian Saigon 1874 secara rasmi dan segera kepada China juga menyebabkan China pada awalnya tidak memberikan reaksi tentang perjanjian tersebut. Ini kerana pada pandangan Vietnam, Perjanjian Saigon 1874 dengan Perancis lebih dilihat sebagai satu perjanjian biasa untuk urusan perdagangan dan perniagaan (Treaty of Peace and Alliance). ${ }^{21}$ 
Ini kerana pada 31 Ogos 1874, sebuah lagi perjanjian perdagangan telah ditandatangani di antara Vietnam dengan Perancis. ${ }^{22}$

Namun, pada 1875, apabila berlaku peristiwa pembunuhan seorang penyelidik British bernama Augustus Margary, British telah meminta China membuka perdagangan kepada British di sempadan YunnanBurma. Peluang ini segera diambil oleh Perancis untuk turut sama meminta China membuka pintu perdagangannya di Sungai Merah. ${ }^{23}$ Comte de Rochechouard (1831-1879), duta Perancis di China telah meminta China mematuhi Perkara 12 dalam syarat Perjanjian Saigon 1874 iaitu membenarkan hak belayar kepada Perancis di Sungai Merah sehingga ke Yunnan. ${ }^{24}$ Lantaran itu, sebahagian daripada pegawai istana di China berpendapat bahawa dua cara sahaja yang dapat menyelamatkan negara Vietnam daripada terus ditakluki oleh Perancis. Pertamanya, mengeratkan kembali hubungan tributari dengan Vietnam dan keduanya, mengadakan rundingan dengan pihak Perancis. ${ }^{25}$

\section{Hubungan Tributari China-Vietnam}

Hubungan tributari antara China-Vietnam masih berlangsung walaupun Perancis sudah menakluki sebahagian daripada bumi Vietnam melalui Perjanjian Saigon 1874. Namun, utusan tributari yang diketuai oleh Tran Khanh Thuan dan penolongnya Nguyen Thuc serta Nguyen Hoan merupakan utusan tributari yang terakhir oleh Vietnam kepada China. ${ }^{26}$ Apabila utusan tersebut tiba di Beijing pada 20 Mac 1882, ia disambut dengan meriahnya dan ditempatkan di Shenwumen (Gate of Divine Military Genius) sebelum dibenarkan mengadap Maharaja Guangxu (1875-1908). ${ }^{27}$ Keprihatinan China terhadap utusan Vietnam jelas terbukti apabila Maharaja Guangxu telah menghadiahkan kain-kain sutera kepada mereka kerana pada pandangan Maharaja Guangxu, pakaian ahli-ahli rombongan Vietnam kelihatan sedikit lusuh dan agak daif. ${ }^{28}$ Seterusnya Maharaja Guangxu melalui Gabenor Guangxi, Qing Yu menegaskan bahawa Vietnam merupakan negeri naungan China dan berpesan kepada Vietnam agar menguatkan jati diri demi kedaulatan negara. ${ }^{29}$

Pada tahun 1882, apabila Perancis melalui Le Myre de Vilers, Gabenor di Cochin China cuba menawan Hanoi, Maharaja Tu Duc segera mengutus surat kepada Maharaja Guangxu (1871-1908) untuk memohon bantuan dari China. Antara lain beliau menyatakan bahawa Vietnam telah berpayung di bawah naungan China untuk sekian lamanya. Oleh itu, setiap inci tanah dan setiap rakyat di Vietnam adalah hak milik China. Lantaran itu, China bertanggungjawab menjaga kedaulatan dan mempertahankan Vietnam sebagai negara naungannya. Lalu beliau memohon kepada China agar tidak membiarkan bumi 
Vietnam daripada terus dicerobohi oleh Perancis tanpa mengambil sebarang langkah mempertahankan Vietnam. ${ }^{30}$

Utusan surat untuk mendapatkan anungan ini bukanlah satu perkara baru, malah sejak tahun 1879 lagi, Maharaja Tu Duc telah mengutus surat kepada Maharaja Guangxu. Baginda memperakui bahawa Vietnam akan terus akur menjadi negeri naungan China dengan mempersembahkan ufti tahunan dan ikrar ketaatsetiaan para pembesarnya terhadap China. ${ }^{31}$ Ini kerana pada pendapat Maharaja Tu Duc, kemakmuran China telah membawa kesentosaan kepada Vietnam. Tetapi semasa era pemerintahan Maharaja Xianfeng (18501861), China menghadapi masalah dengan Barat menyebabkan China terpaksa "menyepi" sementara daripada Vietnam. Natijahnya, ini menyebabkan enam wilayah di Vietnam terlepas kepada Perancis yang turut menjejaskan sumber kewangan Vietnam. ${ }^{32}$

Selain akur terhadap desakan Vietnam meminta bantuan, China sesungguhnya sedar bahawa Perancis telah sekian lama menaruh dengan penuh minat terhadap bumi Vietnam. Apatah lagi dalam keadaannya yang lemah, sememangnya Vietnam tidak berupaya untuk menangkis serangan-serangan dari Perancis secara bersendirian ${ }^{3{ }^{3}}$ Ini ditambahi pula kejayaan Perancis memperoleh hak untuk memudiki sehingga ke Sungai Merah (Song Hong). Perkembangan ini tentunya menjadi ancaman kepada China kerana dengan pembukaan Sungai Merah bermakna Perancis akan dapat memudiki sehingga ke Yunnan di China. Lantaran itu, China khuatir bahawa terjejasnya keselamatan Vietnam juga akan mengugat kedaulatan China. Kedudukan dan lokasi Vietnam merupakan pagar kepada China. Keruntuhan Vietnam bermakna robolnnya pagar China. ${ }^{34}$ Ini sepertimana ditegaskan oleh Liu Zhangyou (1818-1887), Gabenor Jeneral di Wilay ah Shanxi seperti berikut:

Negeri-negeri di sempadan China adalah pintu. Manakala negeri tributari China adalah pagarnya. Kita [China] mendirikan pagar untuk melindungi pintu kerana pintu dapat menjamin keselamatan rumah. Sekiranya pagar terjelabak, maka pintu akan beroleng-oleng manakala sekiranya pintu dalam keadaan beroleng-oleng, maka rumah [China] akan menghadapi bencana. ${ }^{35}$

Sementara itu, Zhou Derun (?-1892), neige xueshi (Academician of the Grand Secretariat) ${ }^{36}$ dalam usulnya kepada Maharaja Guangxu menegaskan bahawa:

Penawanan Vietnam merupakan satu malapetaka kepada China seolah-olah kata bidalan China "zhenlin giefu, chunwang chi han." ${ }^{\prime 37}$ Sekiranya China terus mengambil sikap tidak peduli, ia akan 
membawa keruntuhan sistem tributari. Bukan setakat Kepulauan Ryukyu tidak boleh dikembalikan, malah negeri-negeri seperti Korea dan Mongolia akan sukar dipertahankan sebagai negeri naungan China lagi. ${ }^{38}$

Lantas beliau tegas meminta China mengambil langkah sewajarnya kerana pada pendapatnya sekiranya China kehilangan Vietnam, ia akan memberi impak yang besar kepada kemandiran Dinasti Qing di China dan negeri-negeri naungan China yang lain. ${ }^{39}$ Konsep "zhenlin qiefu, chunwang chi han" yang disuarakan oleh Zhou Derun mendapat sokongan daripad para pegawai China di Akademi Hanlin. ${ }^{40}$ Lantaran itu, golongan ini terus mendesak agar China mempertimbangkan pendekatan "Baoyue gubian" iaitu strategi mempertahankan kedaulatan Vietnam dengan mengukuhkan tahap keselamatan sempadan di China. ${ }^{41}$ Suara mereka telah dikenali sebagai suara rijia (roice of the literati) $^{42}$ dan mereka telah menubuhkan Qing Liutang (Party of the Purits). ${ }^{43}$ Antaranya mereka ialah Zhang Peilun (1848-1903), ${ }^{44}$ Gabenor Jeneral Liangguang, Zhang Shusheng (1824-1884), ${ }^{45}$ Gabenor Jeneral Liangjiang, Liu Kunyi (1830-1902), Gabenor di Shanxi dan juga Gabenor Zhang Zhidong (1837-1909) yang terkenal dengan usulnya yang mengutarakan bahawa mempertahankan keselamatan empat wilayah suku kaum orang asing (Babarian of the four quaters) yang mengelilingi China lebih baik daripada berwaspada terhadap penjajahan luar dari arah utara, selatan, timur dan barat yang dikenali sebagai strouri shou sijing, buru shou siyi. ${ }^{46}$

Sesungguhnya, para pembesar tersebut berpendapat bahawa China perlu mempertahankan sistem tributari dalam hubungan China dengan Vietnam. Ini kerana dengan mempertahankan hubungan tributari tersebut bererti China mempunyak hak naungan ke atas Vietnam. Langkah ini tentunya dapat membantu menghalang usaha penjajahan Perancis ke atas Vietnam. Seterusnya langkah ini dapat memelihara keamanan di bahagian barat-daya China dan juga kawasan-kawasan sepanjang sempadan China-Vietnam. ${ }^{47}$ Lantaran itu, demi menjaga keselamatan Vietnam dan kedaulatan China sendiri, China lantas mengemukakan bantahan terhadap usaha-usaha penaklukan Perancis ke atas Vietnam. China telah mengusulkan pelbagai pendekatan melalui hubungan tributari yang terjalin demi ... Ik menyelamatkan Vietnam daripada terus dijajah oleh Perancis.

\section{Pendekatan Politik}

Dari segi pendekatan politik, China bertekad untuk mempereratkan lagi hubungan dengan Vietnam demi mencari penyelesaian bersama 
menghadapi kemelut ini. Zeng Jize atau juga dikenali sebagai Marquis Tseng (Tseng Chi-tse, 1839-1890), duta China ke British dan Perancis (1878-1884) (18 $^{4}$ merupakan antara pembesar istana China yang begitu lantang memperjuangkan agar China dan Vietnam memperkukuhkan kerjasama yang lebih erat dalam menghadapi tusukan bertubi-tubi dari Perancis. ${ }^{49}$ Beliau berpendapat bahawa hanya dengan hubungan dan kerjasama yang erat antara kedua-dua negara, ia akan dapat menyingkirkan kuasa-kuasa asing termasuk Perancis dari bumi Vietnam. ${ }^{50}$ Pada 15 Disember, 1881, Zeng Jize telah mengusulkan kepada Maharaja Guangxu beberapa cadangan menyelamatkan Vietnam yang dikenali sebagai chouyue shi qitino (Tujuh Usul Menyelamat Negara Vietnam). ${ }^{51}$ Antara lain ialah dalam aspek hubungan diplomatik. Zeng Jize menyarankan kepada wewenang China agar membenarkan Vietnam menempatkan pegawai-pegawainya di Beijing supaya apa jua saranan dari China dapat disalurkan kepada Vietnam dengan kadar segera. Zeng Jize juga mengusulkan agar kedutaan China di Perancis dapat memberi ruang dan tempat kepada pegawai-pegawai Vietnam supaya mereka boleh bertindak sebagai perantara dalam menyelesaikan masalah yang melibatkan kedua-dua negara. Manakala dalam aspek ketenteraan, Zeng Jize mencadangkan agar Angkatan Laut China mengambil-alih Sungai Merah untuk membolehkan China mengawasi dan melindungi Vietnam secara mutlak. Dengan langkah ini, beliau berharap Vietnam dapat menghindari daripada terus dicerobohi oleh pihak barat khususnya Perancis. ${ }^{52}$

Selain itu, China juga menghantar pegawainya ke Vietnam untuk menyiasat perkembangan terkini yang berlaku di Vietnam. China berharap tindakan sedemikian membolehkan kedua-dua buah negara dapat bertukar-tukar maklumat dan perisikan supaya suatu jalan penyelesaian yang tuntas dapat dikemukakan untuk menentang kemaraan Perancis di Vietnam. ${ }^{53}$ Pada 15 Mac 1881, hasil daripada usul yang dikemukakan oleh Chen Baoshen dan Zhang Peilun kepada Maharaja Guangxi, istana China bersetuju mengarahkan Tang Yangeng ke Vietnam berjumpa dengan Maharaja Tu Duc (1829-1883) untuk menjalinkan hubungan dan kerjasama yang lebih padu demi mengusir Perancis dari Vietnam. ${ }^{54}$ Chen Baoshen dan Zhang Peilun berpendapat bahawa status Tang Yanggeng sebagai pengurus China-Merchants Steam Narigation Company di Guangzhou (Canton) tidak akan menimbulkan syak di pihak Perancis. Di samping itu, mereka juga berpendapat Tang Yanggeng seorang yang berkaliber dan berdiplomasi dilantik sebagai Leftenan Gabenor di Guangxi atas cadangan Zhang Peilun dan Zhang Shusheng. ${ }^{55}$ 
Pada Februari 1882, Tang Yangeng bersama dengan Huang Guoan, Pan Tangjing dan Zhou Binglin berangkat ke Vietnam. Namun pemergian utusan China masih berselindung di sebalik alasan kononnya untuk menguruskan urusan pengimportan beras dan perniagaan antara China dengan Vietnam. Langkah ini diambil kerana China tidak bersedia lagi berkonflik secara terang-terangan dengan Perancis. ${ }^{50}$ Misi Tang Yanggeng gagal berjumpa dengan Maharaja Tu Duc kerana baginda khuatir perjumpaan ini akan menimbulkan kesangsian di pihak Perancis. ${ }^{57}$ Namun, Tang Yanggeng berjaya bertemu dan berbincang dengan para pembesar Vietnam seperti Nguyen Van Tuong, thuong-thi (president) di ho-bo (Board of Finance) dan Tran Thuc Dam, penasihat raja yang berpengaruh. ${ }^{58}$ Dalam pertemuan tersebut, Tang Yangeng memaklumkan kepada Nguyen Van Tuong dan Tran Thuc Dam akan muslihat Perancis untuk menakluki utara Vietnam dan meminta Vietnam perlu lebih berwaspada..$^{59}$ Walaupun China dan Vietnam gagal mengemukakan satu rancangan yang mantap untuk mengusir Perancis dari bumi Vietnam secara total, namun Vietnam telah memohon kepada China agar dapat memenuhi pemintaan-permintaan mereka seperti berikut:

a) Menubuhkan kedutaan Vietnam di Beijing supaya dapat melaporkan kepada Zongli Yamen (Tsungli Yamen-Kementerian Luar China) dengan kadar yang segera apa-apa jua perkara yang mustahak melibatkan hubungan diplomatik antara kedua-dua buah negara.

b) Menempatkan pejabat pewakilan Vietnam di Guangdong supaya para peniaga Vietnam dan China dapat saling bertukar-tukar risikan dan maklumat dengan China tentang kegiatan Perancis di Vietnam.

c) Memberi keizinan kepada para pengawai (utusan yang menghantar tibutari) Vietnam menaiki mana-mana kapal hak milik China supaya mereka boleh belayar ke mana-mana dalam pelosok dunia. ${ }^{\text {(i) }}$

Tuntutan-tuntutan tersebut seperti mana laporan Tang Yanggeng dilihat sebagai terkehadapan dan berbeza daripada norma-norma kebiasaan yang diamalkan dalam konteks hubungan tributari ChinaVietnam. ${ }^{61}$ Tuntutan tersebut menggambarkan bahawa Vietnam pada hakikatnya memerlukan hubungan yang lebih erat dengan China. Walaupun akhirnya tuntutan dan cadangan tersebut hanya tinggal sebagai tuntutan sahaja kerana ia tidak dapat dilaksanakan oleh China, namun jelas Vietnam menyedari bahawa dalam keadaan genting ini, mereka masih berkiblatkan China kerana memerlukan bantuan China berbanding dengan mana-mana pihak yang lain. 
Selain itu, China juga mengarahkan Tang Jingsong (1841-1903), pegawai Setiausaha di Jabatan Hal Ehwal Awam ke Vietnam untuk menyiasat keadaan di Tonking. ${ }^{62}$ Misi utama Tang Jingsong ialah menjadi jurucakap untuk mengadap Maharaja Tu Duc supaya memujuknya tidak mengusir Kumpulan Bendera Hitam pimpinan Liu Yongfu (18371917) keluar dari Vietnam kerana desakan dari Perancis. Di samping itu, Tang Jingsong juga berharap lawatannya akan memberi sokongan moral kepada Vietnam agar tidak gentar menghadapi Perancis dan menyedarkan mereka supaya tidak terpengaruh dengan segala janji manis Perancis yang kononnya dengan penyerahan hak kedaulatan wilayah kepada Perancis akan membantu melonjakkan sektor ekonomi dan pembangunan wilayah-wilayah di Vietnam. ${ }^{6.3}$

Pada 25 Mac 1883, sekembalinya Tang Jinsong dari Tonking, beliau telah mengemukakan usulnya untuk memperkukuhkan hubungan China-Vietnam yang dikenali sebagai xiangdu bianqing tino chenban fazhe (Butiran Lanjut Usul-Usul Untuk Menyelamatkan Sempadan Negeri China daripada Penjajahan Perancis) kepada China. ${ }^{64}$ Beliau berpendapat bahawa China wajar menghulurkan bantuan dan memberi pengiktirafan kepada Kumpulan Bendera Hitam. Lalu beliau mencadangkan agar China mengerahkan tentera dari wilayah-wilayah di Yunnan, Guilin dan Guangdong ke Vietnam untuk bersama-sama tentera China menentang penjajahan Perancis. Namun, Tang Jingsong mencadangkan agar pengiktirafan dan bantuan yang dihulurkan kepada Kumpulan Bendera Hitam diperakui oleh China secara berselindung demi mengelak daripada berkonflik secara terang-terangan dengan Perancis. Di samping itu, beliau juga menyarankan agar kemandiran orang Cina di Vietnam tidak dilupakan oleh China. Kerajaan China sewajarnya mendekati dan menghubungi golongan ini agar mereka tidak dipergunakan oleh Perancis, sebaliknya tenaga dan kepakaran mereka boleh dimanfaat oleh wewenang China. ${ }^{65}$

Namun begitu, dalam soal pengiktirafan terhadap Kumpulan Bendera Hitam, Zeng Jize mempunyai pandangan yang berbeza. Ini kerana beliau telah menyarankan agar sokongan tersebut diberi secara terang-terangan. ${ }^{66}$ Pada pendapat Zeng Jize, China sepatutnya mengiktiraf kedudukan sah Kumpulan Bendera Hitam untuk mengelakkan Perancis daripada mengusir mereka kerana selama ini Perancis melabelkan mereka sebagai "penyangak" dan "pengacau" yang menimbulkan huru-hara di sempadan China-Vietnam. Zeng Jize menyedari bahawa Kumpulan Bendera Hitam merupakan tulang belakang dalam siri-siri penentangan Vietnam dengan Perancis. Apatah lagi Perancis melihat kumpulan ini sebagai duri dalam daging mereka dalam usahanya menawan Vietnam. Kegagahan Kumpulan Bendera Hitam menentang askar Perancis terbukti apabila Jules Ferry (1832- 
1893), Perdana Menteri Perancis pernah mezahirkan kebimbangannya bahawa:

...kita [Perancis] mempunyai pelbagai cara untuk menawan [Vietnam]. Semua lebih kepada omong-omong kosong! Selagi Kumpulan Bendera Hitam ada [di Vietnam], semuanya tidak akan berjaya dilaksanakan [untuk menawan Vietnam]. ${ }^{6 \%}$

Lantaran itu, pada 18 September 1883, Zeng Jize telah menegaskan kepada Jules Ferry bahawa "China tidak boleh tidak memperd ulikan nasib Kumpulan Bendera Hitam." 68 Nam un, pada 19 Disember, 1883, Jules Ferry bertegas mahu menghapuskan kumpulan ini hingga ke akar-umbi. Lalu Zeng Jize melapor dan mengusulkan kepada Zongli Yamen tentang kezaliman Perancis dan meminta China mengiktiraf dan melarang sebarang usaha untuk menghapuskan Kumpulan Bendera Hitam. ${ }^{69}$ Oleh itu, apabila Li Hongzhang (1823-1901), Gabenor di wilayah Zhili (Hebei) (1870-1950) mewakili China dalam Rundingan Li-Fournier 1883 dengan Perancis, Maharaja Guangxu telah mengarahkan kepada Li Hongzhang supaya tidak bersetuju dengan apa jua syarat yang dibangkitkan oleh Perancis berkaitan dengan pengusiran Kumpulan Bendera Hitam dari Vietnam. ${ }^{70}$ Pendekatan menyelamat dan mengiktiraf Kumpulan Bendera Hitam oleh China terbukti merupakan langkah yang tepat apabila kumpulan ini akhirnya menjadi benteng dan penggempur utama dalam Perang China-Perancis yang tercetus pada 1883.

Sesungguhnya pendekatan politik melalui rundingan tersebut telah diadakan antara Li Hongzhang (1823-1901) dengan Frederic Albert Bouree (1836-1914), duta Perancis di Beijing semenjak September 1882 lagi untuk menyelamatkan Vietnam daripada dijajah oleh Perancis. China telah memaklumkan kepada Vietnam agar menghantar pegawaipegawai Vietnam yang berkaliber untuk turut sama ke Tianjin dalam usaha China mencari jalan penyelesaian melalui rundingan tersebut. ${ }^{\prime \prime}$ Vietnam telah menghantar Pham Than Dat, thuong-thu (President) ${ }^{72}$ dan Nguyen Thuat, thi-lang (vice president) ${ }^{7}$ yang masing-masing dari Hinhho (Board of Justice) sebagai wakil Vietnam dalam rundingan tersebut. ${ }^{74}$ Dalam rundingan tersebut, China dan Perancis telah mencapai resolusi dan bersetuju pada dasarnya syarat-syarat berikut:

a) Meminta China mengundurkan angkatan tenteranya dari Vietnam kerana menurutnya Perancis tidak berniat untuk menghakis dan mengambil kuasa ke atas Vietnam.

b) China dan Perancis masing-masing dibenarkan mendirikan pusat pengutipan cukai dan kemudahan pemasaran mereka di Lao Cai (juga dikenali Lao Kay atau Laokai) berhampiran dengan Sungai Merah. 
c) Pembahagian sempadan yang jelas antara China dan Perancis. Kaw asan utara Vietnam di bawah perlindungan China, manakala Perancis menaungi wilayah-wilayah di selatan Vietnam. Namun kedua-dua negara ini bersetuju melindungi utara Vietnam daripada sebarang pencerobohan kuasa sing yang lain. ${ }^{75}$

Namun begitu, siri rundingan tersebut tidak mencapai kejayaan kerana ditolak oleh Jules Ferry yang menggantikan Charles de Freycinet sebagai Perdana Menteri Perancis. Beliau berpendapat bahawa cadangan dan syarat yang dikemukakan oleh Frederic Albert Bouree dilihat terlalu "mengalah" kepada China dan "merendahkan" status Perancis sendiri serta bertentangan dengan Perjanjian Saigon 1874 y ang telah pun memperakui hak-hak keistimewaan Perancis ke atas wilayahwilayah di Cochin China. ${ }^{76}$ Arthur Tricou (1837-1917), duta Perancis ke Jepun telah dilantik sebagai wakil khas (Envoye Extraordinaine) menggantikan Bouree untuk berunding dengan China. ${ }^{77}$

Lantaran itu, China terpaksa mengusahakan pendekatan lain untuk menyelamatkan Vietnam. China memberi tafsiran baru dalam konteks hubungan tributari dengan Vietnam. China memperkukuhkan hubungan tributari dengan Vietnam agar dapat menebus kembali hak kedaulatannya terhadap wilayah-wilayah di Vietnam. China yang diwakili oleh Zeng Jize telah memulakan perbincangan dan perdebatan tentang konsep tributari dengan Perancis. Oleh itu, pada 20 September, 1881, Zeng Jize yang berada di St. Petersburg, Rusia bingkas membuat bantahan rasmi kepada Kementerian Luar Perancis melalui Antoine Chanzy (1823-83), Duta Perancis di Russia tentang kemasukan tentera Perancis ke Tonking. Beliau menegaskan bahawa,

\footnotetext{
Vietnam telah lama menerima kurnian China dan mereka merupakan negeri naungan China. Sekiranya berlaku apa-apa perkara mustahak di dalam negeri Vietnam, China tidak boleh diabaikan apatah lagi tanpa dimaklumkan. ${ }^{78}$
}

Namun begitu, reaksi Bouree, yang telah dilantik sebagai Minteri Luar Perancis terhadap bantahan Zeng Jize ialah "Tonking adalah negara naungan Annam [Vietnam]. Manakala Annam [Vietnam] merupakan negeri perlindungan Perancis. Oleh itu, tidak timbul Annam [Vietnam] milik China." ${ }^{79}$ Selepas menyelesaikan konflik di antara China-Rusia (1879-1880) berkenaan dengan pertelingkaian hak kedaulatan ke atas wilayah Ili (Xinjiang), ${ }^{80}$ Zeng Jize segera memberikan reaksinya kepada Perancis bahawa, 
Sempadan Vietnam dengan China adalah bertautan seperti aur dengan tebing. Dengan menjaga kelangsungan Vietnam, China sebenarnya menjaga kelangsungan wilayah-wilayah di dalamnya [China]..$^{81}$

Tegasnya lagi bahawa, "walaupun rundingan demi rundingan diadakan sama ada di Shanghai mahupun Paris; persoalan sekarang ialah China tetap memperakui Vietnam sebagai negeri naungannya." ${ }^{22}$ Namun, bantahan-bantahan melalui saluran diplomatik yang disuarakan oleh Zeng Jize tidak membawa sebarang kejayaan. Ini diakui sendiri oleh beliau bahawa,

Biarpun berbuih mulut kita membantah [kepada Perancis] secara diplomatik tentang pencerobohan mereka [Perancis] di Vietnam dan mempertikai syarat-syarat dalam perjanjian yang telah ditandatangani oleh mereka [Perancis]. Mereka [Perancis] telah bertekad mahu menawan Vietnam. Mereka [Perancis] tidak akan melepaskannya dengan begitu mudah lagi. ${ }^{83}$

Lantaran itu, demi mengukuhkan hubungan tributari yang sedia terjalin, adat-istiadat tradisional penabalan raja Vietnam telah diberi keutamaan oleh China. Maharaja Ham Nghi (1884-1885) yang mewarisi takhta di Vietnam berharap dapat menghantar utusan ke China untuk mendapat perkenan dari Maharaja China dan menerima pengiktirafan sebagai Maharaja Vietnam yang baru. ${ }^{84}$ Maharaja Ham Nghi berharap dengan perkenan serta pengesahan keabsahan daripada Maharaja China, ia akan dapat mengurangkan penjajahan Perancis ke atas Vietnam. ${ }^{85}$

Sementara di pihak China pula, utusan tributari dan istiadat penabalan merupakan acara yang dinantikan-nantikan oleh mereka kerana status Vietnam sebagai negeri naungannya telah menjadi bahan polemik yang tidak berkesudahan antara China dan Perancis. China berharap dengan kedatangan utusan Vietnam akan memperkuatkan fakta dan bukti bahawa Vietnam selama ini merupakan negeri naungan mereka. Lantaran itu, China berharap bahawa sebagai negara yang menaungi Vietnam, maka keputusannya untuk berdamai mahupun berperang dengan Perancis tidak akan menjadi isu dan polemik. Ini kerana sebagai sebuah negeri naungan China, China mempunyai hak dan kata putus menentukan kedaulatan Vietnam. ${ }^{86}$

Justeru, sebelum utusan tributari Vietnam dihantar ke China. China begitu mengambil berat dan memandang serius terhadap upacara yang dijalankan terhadap sistem tributari tersebut. Malah ada yang mencadangkan agar China melantik dua orang pegawai yang terbilang dalam kalangan yang cemerlang dalam angkatan tentera sebagai utusan dan seterusnya menggunakan kapal menyusuri pinggir 
laut Vietnam untuk menjalankan upacara penabalan Maharaja Ham Nghi (1884-1885). ${ }^{87}$ Walaupun kedua-dua negara ini dilihat begitu bersungguh-sungguh melakukan yang terbaik untuk menjayakan misi dan upacara penghantaran ufti dan penabalan diraja, namun sekali lagi pendekatan ini gagal dilaksanakan kerana beberapa faktor dalaman yang berlaku di Vietnam dan China menyebabkan cadangan ini hanya tinggal sebagai cadangan.

Selain itu, China juga menyarankan agar Vietnam dan China masing-masing perlu memperluaskan skop kerjasama dengan kuasa Barat yang lain selain Perancis. Liu Hongzhang misalnya pernah menjanjikan imbuhan perdagangan kepada British sekiranya British sudi meneroka sehingga ke Vietnam sepertimana yang ditegaskan oleh Konsul Hughes kepada Grosvenor bahawa, "... would not only endeazour to obtain good term for British in Annam [Vietnam] but also exert his [Li Hongzhang] influence in our [British] faoour in Corea [Korea]." 88

Lantaran itu, Zhang Peilun dan Chen Baosheng mengesyorkan agar China bekerjasama dengan Jerman. Menurut mereka, selepas Perancis mengalami kekalahan dalam Perang Franco-Prussian. (18701871), Perancis lebih berwaspada terhadap tindak-tanduk Jerman khususnya di Eropah. Kekalahan ini juga menyebabkan Perancis masih teragak-agak menggerakkan angkatan tenteranya secara besarbesaran ke Timur. Oleh itu, China perlu mengambil kesempatan ini untuk bekerjasama dengan Jerman yang dilihat berupaya menghalang cita-cita Perancis di Vietnam. ${ }^{89}$

Sementara itu, Zeng Jize pula menyarankan agar Sungai Merah dibuka untuk aktiviti perdagangan kepada semua kuasa Barat. ${ }^{50}$ Pada perkiraan beliau, langkah ini perlu diambil agar Perancis tidak lagi menggunakan alasan "larangan perdagangan di Sungai Merah" untuk menawan Vietnam. Zeng Jize menyedari bahawa dengan hanya membenarkan kuasa Barat yang lain seperti British, Jerman dan Amerika Syarikat memasuki Vietnam, ia akan dapat sekurang-kurangnya mengendurkan kuasa utama (superior) dan monopoli Perancis di Vietnam. ${ }^{91}$ Ini kerana kuasa Barat tersebut telah bersaing antara satu sama lain demi menguasai bahan mentah di Timur semenjak tercetusnya Revolusi Industri lagi.

Namun, tawaran China kepada kuasa Barat selain Perancis yang lain juga tidak berjaya. Pada Julai 1880, Jerman telah memaklumkan kepada Quai d'Orsay (Pejabat Perdana Menteri di Perancis) bahawa kepentingan mereka di Vietnam adalah semata-mata faktor ekonomi dan perniagaan. Lantaran itu, Jerman mengalu-alukan usaha-usaha Perancis menguatkan kedudukan politik mereka di Vietnam. Ini kerana Jerman berpendapat bahawa langkah sedemikian secara tidak langsung dapat mengukuhkan keselamatan dan kepentingan mereka di Vietnam. ${ }^{92}$ 
Kegagalan demi kegagalan strategi dan pendekatan melalui saluran hubungan luar (diplomatik) dan saluran politik untuk membendung kemaraan kuasa Perancis menyebabkan China terpaksa mengubah strateginya kepada pendekatan ketenteraan untuk menghadapi kuasa Perancis. Namun, pendekatan ketenteraan yang dikupas dan ditinjau dalam makalah ini sekadar langkah awalan yang diambil oleh China sehingga tahun 1883 dalam usaha mereka mempertahankan Vietnam.

\section{Pendekatan Ketenteraan Peringkat Awal}

Dari segi pendekatan ketenteraan, China telah menggerakkan kekuatan tenteranya untuk membantu Vietnam menghadapi Perancis. Namun bantuan yang dihulurkan itu pada peringkat awal sebelum meletusnya Perang China-Vietnam 1884-1885 adalah pada skala yang agak terbatas dan tidak terbuka. China hanya mengambil pendekatan secara bersembunyi menghadapi penjajahan kuasa Perancis di Vietnam. China telah mengarahkan angkatan tenteranya mara ke Vietnam tetapi dengan alasan membantu Vietnam menghapuskan perompakperompak di sempadan kedua-d ua buah negara. Ini adalah untuk mengaburi pandangan Perancis. China sebaliknya telah menempatkan angkatan tentera yang diketuai oleh Xu Yanxu dari batalion Guangxi di Bac Ninh (Vietnam) dengan kekuatan askar seramai enam ribu orang. ${ }^{93}$ Manakala batalion yang diketuai oleh Tang Tong dari Yunnan dengan kekuatan askar lapan ribu orang pula ditempatkan di Son Tay. ${ }^{9.4}$ Kekuatan angkatan tentera China di Vietnam terus ditambah dari masa ke semasa sehingga kekuatannya mencecah kepada tiga puluh ribu orang menjelang Perang China-Perancis. ${ }^{95}$

Justeru, apabila tentera China masuk ke Vietnam, mereka tidaklah segera mengisytiharkan perang ke atas Perancis. Strategi dan perancangan dari China adalah tidak mahu bertembung secara terbuka dengan Perancis kerana pada tanggapan China Perancis tidak akan berkonflik dengan China. Lalu China melalui junzhi chu (Council of State) berpesan kepada angkatan tenteranya agar tidak "bergerak secara bersendirian." Menurut junzhi chun bahawa, "Kedatangan angkatan tentera dari Yunnan dan Guangdong adalah untuk menghapuskan penyangak-penyangak di Vietnam, mereka [askar-askar China] tidak dibenarkan bertindak lebih daripada batasan tersebut."

Pendirian China pada peringkat awal yang dilihat sebagai masih berbelah-bagi dalam mengisy tiharkan perang ke atas Perancis adalah lantaran pendebatan di kalangan pembesar-pembesar yang tidak sealiran sama ada menggunakan meja rundingan mahupun ketenteraan dalam meleraikan konflik Perancis di bumi Vietnam. Namun, sikap "teramat berhati-hati" China juga merupakan pemangkin yang telah 
membenamkan naungan China kerana Vietnam akhirnya terpaksa menandatangani Perjanjian Hue 1883 yang mengesahkan butiran syarat dalam Perjanjian Saigon $1874 .{ }^{97}$

\section{Kesimpulan}

Tegasnya, selepas Pemberontakan Taiping sehingga ke tahun 1881, hubungan China-Vietnam turut melibatkan Perancis menyebabkan wujudnya hubungan tiga segi yang kompleks. Perancis semakin agresif untuk menawan Vietnam. Lalu Perancis berusaha menafikan ikatan hubungan negeri naungan dan negeri yang dinaungi (vassal-overlordship relationship) antara China-Vietnam melalui Perjanjian Saigon 1874. Namun, hubungan China-Vietnam tidak terlerai kerana mereka tidak memperakui butiran perjanjian tersebut. Sebaliknya China dan Vietnam masih menjalin hubungan tributari melalui penghantaran utusan tributari dan bantuan ketenteraan China kepada Vietnam. Lantaran itu, pendekatan politik yang luas dan pendekatan ketenteraan walaupun dalam skala yang terhad diusahakan oleh China dilihat sebagai langkah cuba mengukuhkan kembali naungan mereka ke atas Vietnam. Namun, usaha-usaha tersebut tidak berjaya sehingga China akhirnya terpaksa melancarkan Perang China-Perancis untuk memelihara kedaulatan Vietnam.

\section{Nota}

1 Antara lain, anggota dalam rombongan tersebut termasuk Francois Garnier, Louis Delaporte, Clovis Thorel, Louis de Corne, Eugene Joubert. Sila lihat Milton Osborne, "Francis Garnier (1839-1873), Explorer of the Mekong River", dlm. Victor T. King, Explorers of South-East Asia: Six Lives, Kuala Lumpur: Oxford University Press, 1995, hlm. 58.

2 Milton Osborne, "Francis Garnier (1839-1873), Explorer of the Mekong River", dlm. Victor T. King (ed.) Explorers of South-East Asia: Six Lives, hlm. 62-63.

3 Tran Trong Kim, Viet Nam Su Luoc, Beijing: Shangwu Yinshuguan, 1992, hIm. 376-382.

$4 \quad$ Ibid. hlm. 367-368.

5 "Laporan Vicomte de Carne, kepada Konsul Perancis di Hanoi", 1869, Vimcomte de Carne, "Voyage er Indo-Chine et dans /'Empire Chinoise", dlm. Stephen H. Roberts, History of French Colonial Policy. 1870-1925, London: F. Cass, 1963, hlm. 423 .

- Hosea B. Morse, The International Relations of the Chinese Empire: The Period of Submission 1861-1893, Vol. II, London: Longmans Green, 1910, hIm. 344. Stephen H. Roberts, History of French Colonial Policy. 1870-1925, London: F. Cass, 1963, hlm. 423-424.

s D.G. E. Hall, A History of South-east Asia, London: Macmillan Press, 1981, him. 790 . 
- Hu Sheng, From the Opium War to the May Fourth Movement, Beijing: Foreign Languages Press, 1991, hlm. 520.

10) Perang Prusia-Perancis atau juga dikenali Franco-German War adalah peperangan di antara Perancis dengan German. Perang ini berjaya menamatkan Empayar Kedua di Perancis. Republik Ketiga yang menggantikannya mengamalkan dasar anti-imperial. Untuk maklumat lanjut, sila lihat Lawrence Dinkelspiel Steefel, Bismarck, the Hohenzollern Candidacy, and the Origins of the Franco-German War of 1870, Cambridge: Harvard University Press, 1962, hlm. 195-216.

11 Republik Ketiga adalah satu "governing body" yang ditubuh pada 4 September, 1870, selepas Napoleon's ditangkap oleh pihak Prussians di Sedan dalam Perang Franco-Prussian. Jeneral Lou is Jules Trochu and ahli politik, Leon Gambetta telah membubarkan Empayar Kedua dan mengasaskan "Government of National Defence" yang kemudian menjadikan Perancis sebagai Republik Ketiga, iaitu sebuah republik yang mengamalkan demokrasi berparlimen. Sila lihat Leslie Derfler, The Third French Republic, 1870-1940, Princeton, N. J.: D. Van Nostrand, 1966, hIm. 11-21.

12 Nicholas Tarling (ed.), Jianqiao Dongnamya Shi I (The Cambridge History of Southeast Asia 1), terj. He Hengda et.al., Kunming: Yunnan Renmin

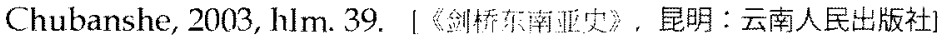

13. Philastre berjaya menandatangani dua persetiaan dengan pihak Vietanm pada 5 hb Januari 1874 dan 7 b Februari 1874. Sila lihat Thomas Edson Ennis, French Policy and Developments in Indochina, Chicago: University of Chicago Press, 1936, hIm. 46.

14 Dai Nam Thuc Luc Climh Bien De Tu Ky, (Primary Compilation of the Veritable Records of the Fourth Reign of Imperial Vietnam), Vol. 49.

15 Sila lihat "Fa Guo He An Nam Guo Wang He Meng Tiao Yue", (France And Annam Peaceful Treaty), dlm. Guoji Tiaoyue Ji, Juan Er, (Collection of International Treaty, Vol. 2: 1872-1916), 1986, Beijing: Shi jie zhi shi chu

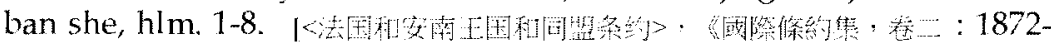

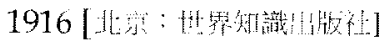

16 Harley Farnsworth MacNair, Modern Chinese History, Selected Readings: A Collection of Extracts from Various Sources Chosen to Mllustrate Some of the Chief Phases of China's International Relations During the Past Hundred Years, Shanghai: Commercial Press, 1923, hlm. 478.

Hosea B. Morse, The International Relations of the Chinese Empire..., hlm. 346-347.

is "Laporan persendirian Alfred N. Rambaud tentang Jules Ferry", Paris, 1903 dIm. Shao Xunzheng, Zlongfa Yuenan Guanxi Shimo (A Complete Account of China-French Relations Concerning Vietnam), Shijiazhuang: He bei

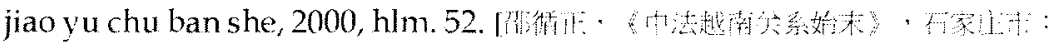

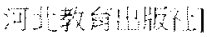

19. Loyd Eric Eastman, Throne and Mandarins: China's Search for a Policy during the Sino-French Controversy, 1880-1885, Cambridge: Harvard University Press, 1967, hlm. 33.

2u Wang Daso, Zhong Guo Chi Dai Shi Kang, Taipeh:, 1975, hlm. 143. 
21 "Le [Nguyen] gouvernement annamite interpreta la remise de l'indemnite et la livaison d'armes comme une sorte de rancon payee par la France; devant ses peoples il se donne l'apparence d'une triomphe", G. Hanotaux and A. Martineau (eds.), Histoire des colonies francaises et de l'expansion de la France dans le monde, Vol. 5, Paris: Plon, 1929-33, hlm. 419 dlm. Shao Xunzheng, Zhongfa Yuenan Guanxi Shimo, hlm. 70.

22 Sesungguhnya, perjanjian tersebut adalah untuk pengesahan (endorsenent) terhadap Perjanjian Saigon 1874 yang telah ditandatangani antara Vietnam dengan Perancis. Sila lihat Hosea B. Morse, The International Relations of the Chinese Empire, hlm. 245.

23 "Telegram Duke Decaizes kepada Count de Rochechouart", 3 Julai 1875, Diplomatic Corresponde (15 Mac 1874 - 13 Nov. 1883) d1m. FO 422/1.

24 "Surat Count de Rochechouart kepada Putera Kung ", 24 Mei 1875, Diplomatic Corresponde (15 Mac 1874 - 13 Nov. 1883) dlm. FO 422/1.

25 Wang Shengzu (ed.), Guo li Guan Xi Shi (History of Internation Relations),

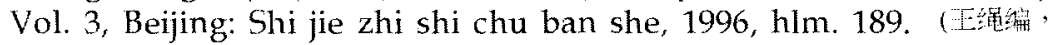

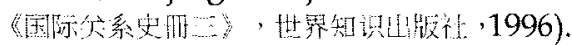

26 Dai Nan Thuc Luc Chinh-Bien De Tu Ky (Primary Compilation of the Veritable Records of the Fourth Reign of Imperial Vietnam), Vol. 63, hlm.

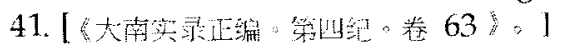

27 Dezong Shilu (Veritable Record of Emperor Guangxu), Vol. 131, hlm.16-17.

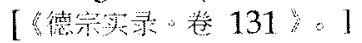

28 R. S. Gundry, China and Her Neighhours: France in Indo-China, Russia and Clina, India and Thibet, London: Chapman and Hall, 1893, hlm. 140.

29 "Laporan Qingyu kepada Maharaja Guangxu tentang keberangkatan utusan tributari Vietnam", 28 Januari 1882, dlm. Qing Guangxu Clao Zhongfa Jiaoshe Shiliao (Historical Materials of Sino-France Negotiation During Emperor

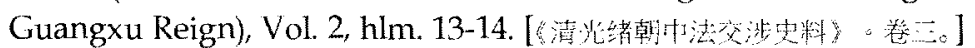

30 "Surat rasmi (ziwen 泬史) Maharaja Vietnam kepada Maharaja Guangxu melalui Gabenor Jeneral Liangguang, Zeng Guoquan", 22 Februari 1882, dlm. Qing Guangxu Chao Zlongfa Jiaoshe Shilino, Vol. 3, hlm. 37.

31 Long Yonghang, "Jindai Zhongyue Zongfan Guanxi Lunyi", Dongnanya Yanjiu, (Southeast Asia Studies), No. 1-2, hlm. 82, 1987.

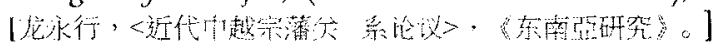

32 Ibid.

33 Shoun Sone, Ho Elsu Koheiki (Record of the Sino-French War), terj. Wang

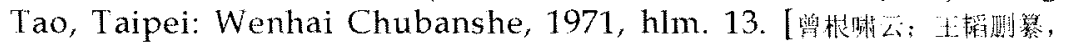

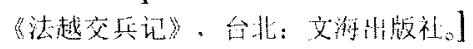

34 Long Yonghang, "Jindai Zhongyue Zongfan Guanxi Lunyi", hlm. 82.

is "Memorial Liu Zhangyou kepada Junchi chu", 8 Nov 1881, dlm. Lit Wushen Kungyi Shu (The Collected Tributaries of Liu Zhangyu), Vol. 7, hlm. 33-38.

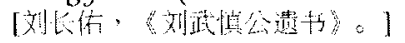

36 Pada tahun 1882, Zhou Derun telah dilantik sebagai Neige Xueshi (Academician of the Grand Secretariat) iaitu jawatan tertinggi rank $2 b$ dalam sistem kerajaan Dinasti Qing di China. Untuk maklumat lanjut tentang biografi Zhou Derun, sila lihat Qingshi Gao (Draf History Of 


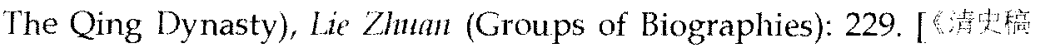

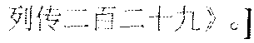

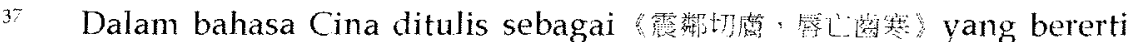
bibir tiada, gigi akan mengigil kesejukan. Dengan pengertian lain adalah sekiranya Vietnam [bibir] tercabut, China [gigi] akan menghadapi bahaya [kesejukan].

38 "Zhou Derun kepada Maharaja Guangxu", 28 Februari 1882, Qing Gunngxu Chao Zhongfa Jiuoshe Shiliao, Vol. 2, hlm. 32.

30 lbid

40 Akademi Hanlin mewakili pusat intelektual tradisi China yang tertinggi dalanı melatih para pegawainya. Sejarah awalnya dapat dikesan semenjak penubuhannya di zaman Dinasti Tang dengan nama Hsueh-Shih-yluan. Namun, akademi ini telah digabungkan ke dalam Neisan Yuan (the forerunner of the Qing Grand Secretariat). Sejak tahun 1670, Akademi Hanlin telah menjadi sebuah institusi yang bebas sehinggalah dibubarkan pada tahun 1906. Sila lihat Adam Y. C. Lui, The Hanlin Academy: Training Ground for the A mbitious, 1644-1850, Hamden, Conn.: Archon Books, 1981, hlm. 1-15.

4) Dalam bahasa Cina ditulis sebagai 保越国边 yang bermaksud mempertahankan Vietnam dengan memperkukuhkan pengawasan di sempadannya.

42 Dalam bahasa Cina ditulis sebagai 《嫱家》. Rujia juga dikenali sebagai fahaman Konfucian. Dalam bahasa Inggeris dikenali sebagai "The School of the Scholars" dan "School of Literati".

43 Dalam bahasa Cina ditulis sebagai 《清流傥 . Qing Lin Tang merupakan barisan para pembesar dari Akademi Hanlin yang berpegang kepada fahaman Konfucian. Antara tokoh-tokohnya ialah Li Hongzao, Gabenor Zongli Yamen, Li Hongzao dan Pan Zuying, menteri-menteri di xingbu (Board of Justice), Huang Tifang, Huang Difang (reader in the Hanlin Academy), Deng Chengxiu (Jiangnan Circuit Censor), Zhang Peilun, Chen Baochen, Zhang Zhidong dan sebagainya. Kumpulan ini menggunakan pendekatan yang lebih agresif. Mereka menentang segala budaya serapan dari Barat. Sila Iihat Eastman E. Lloyd, Throne and Mondarins: China's Search for a Policy During the Sino-French Controversy, 1880-1885. Cambridge: Harvard University Press, 1967, hlm. 206-222.

44 "Usul Zhang Peilun kepada Maharaja Guangxu", 26 Mei $1883 \mathrm{dlm}$. Qing Guangxu Cho Zlongfa Jiaoshe Slitiao, Vol. 2, hlm. 18-21.

45. "Usul Zhang Shusheng kepada Maharaja Guangxu", 11 Ogos $1882 \mathrm{dIm}$. Jbid., Vol. 2, hlm. 21-23.

46 Dalam bahasa Cina ditulis sebagai 所增 Zhidong kepada Maharaja Guangxu", 26 April 1882, dlm. Zhang Wenxiang Gong Quanil (Collected Works of Zhang Wenxiang), Vol 4: Memorial 4,

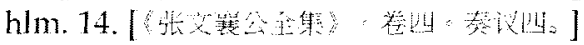

4. Wang Rongsheng, Qingdai Quanshi (Complete History of Qing Dynasty), Vol. 9, Shenyang: liaoning Renmin Chubanshe, 1991, hlm. 106. I1 找箨,

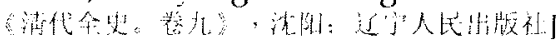


48 Pada Ogos 1878, Zeng Jize dilantik sebagai duta China ke Britain dan Perancis. Pada tahun 1880 pula, beliau dilantik sebagai duta China ke Rusia. Untuk kupasan lanjut tentang penglibatan Zeng Jizen dalam konflik di Vietnam, sila lihat, Li Enhan, Zeng Jize de Waijiao (Marquis Zeng Jize: China's Brilliant Diplomat in the 1870's and 1880's), Nangang: Zhongyan

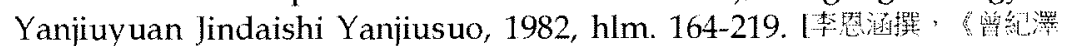

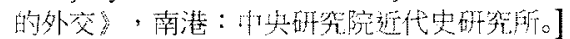

49 Guo Tingyi \& Wang Yujun, (ed.) Zhongfa Yuenan Jiaoshe Dang (The Chinese and French War), Taipei: Zhongyang Yanjiuyuan Jindaishi Yanjiusuo, Vol. 1, hlm. 167, 1962. 譈廷以和上聿均编, 妕法越献交涉 档》, 台北: 吅究研究院近代史研究所。]

50 Zeng Jize \& Yu Yueheng (annotated), Zeng Jize Yiji (The Collected Tributaries of Zeng Jize), Changsha: Yuelu Shushe, 1983, hlm. 201. [雪纪泽；

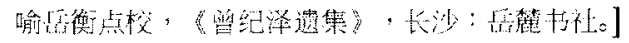

51 Dalam bahasa Cina dikenali sebagai 《然越事t条》

52 "Usul Jeng Jizen kepada Maharaja Guangxu", 15 Disember $1881 \mathrm{dlm}$. Guo Tingyi \& Wang Yujun, (ed.) Zhongfa Yuenan Jiaoshe Dang, Vol. 1, hlm. 213-214.

53 lbid., Vol. 1, hlm. 210.

54 Shao Xunzheng et al., Zhongfa Zhanzheng, Vol. 2, Shanghai: Shanghai

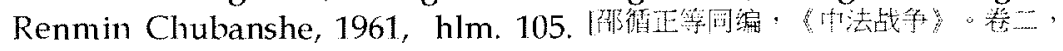
上海：上海人民出版社。

55 Ibid.

56 Huang Guoan merupakan Komander, Pan Tanging pula merupakan majistret manakala Zhou Binglin ialah pegawai tempatan di Zhili. Mereka telah menyamar sebagai peniaga. Sila lihat "Laporan Tang Yangeng kepada Zongli Yamen", 17 Februari 1883, dlm. Ibid., Vol. 3, hlm. 33-34.

57 "Catatan Tang Yangeng dengan Pegawai-Pegawai Vietnam", 11-13 Februari 1882, (Dokumen 140, Lampiran 3), dlm. Ibid., Vol. 1, hlm. 248.

58 Ibid., hlm. 268-270.

59 Ibid., hlm. 210.

60 Ibid, hlm. 273-274 dan lihat juga Dai Nam Thuc Luc Chinh-Bien De Tu Ky, Vol. 66, hlm. 313 .

61 "Laporan Tang Yanggeng kepada Chang Shusheng", 1 Mac 1882 (Dokumen 140, Lampiran 3), Guo Tingyi \& Wang Yujun, (ed.) Zhongfa Yuenan Jiaoshe Dang, Vol. 1, hlm. 273-274.

62 Tang Jingsong berasal dari Guangxi. Semasa pemerintahan Maharaja Tongzhi lagi, beliau adalah jinshi (Graduate). Pada tahun 1891 menjawat sebagai Leftenan Gabenor di Taiwan. Sementara itu, pada tahun 1894 menjawat sebagai Gabenor. Namun, selepas Perjanjian Shimonoseki ditandatangani oleh China dengan pihak Jepun, Taiwan telah diserahkan kepada Jepun. Beliau telah bersama-sama rakyat Taiwan menentang pendudukan Jepun. Pada 25 Mei 1895, Tang Jingsong menjadi Presiden pertama bagi Taiwan (Republic of Farmosa) apabila Taiwan mengisytiharkan mereka bebas dari penguasaan China. Pengisytiharan tersebut merupakan satu muslihat kerana langkah ini cuba mengelak penaklukan Jepun di Taiwan. Tetapi pada $29 \mathrm{Mei}$, 1895, Jepun terus 
menakluki utara Taiwan. Ini menyebabkan Tang Yanggeng melarikan diri semula ke Tanah Besar China. Manakala pada 4 Jun 1895, tempat beliau diganti oleh Liu Yongfu. Untuk makl umat lanjut tentang sejarah Taiwan, sila lihat Chen Kongli, (ed.) Taiwan Lishi Gangyao (An Outline History of

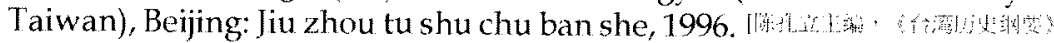

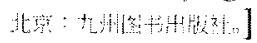

1.3 Tang Jingsong, Qingying Riji (A Volunteer's Dairy), Vol. 1, Taipei: Wenhai

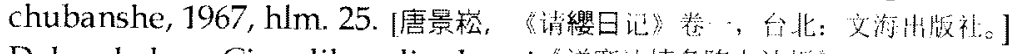

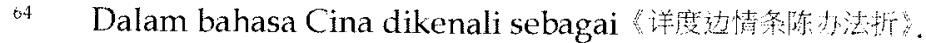

65. Tang Jingsong, Qingying Riji, hlm, 25.

б́ Guo Tingyi dan Wang Yujun (ed.), Zhongfa Yuenan Jiaoshe Dang, Vol. 2, hlm. 939.

67. Ibid., Vol. 3, hlm. 1612.

* "Percakapan antara M. Jules Ferry dengan Zeng Jize (Marquis Tseng)", 18 September, 1883, Diplomatic Correspondence (15 Mac $1874-13$ Nov., 1883) dIm. Foreign Office (FO) 421/1.

69 Shao Xunzheng et.al., Zhongfa Zhanzheng, Vol. 7, hlm. 190 dan juga Guo Tingyi dan Wang Ýujun (ed.), 7 honfa Yuenan Jiaoshe Dang, Vol. 3, hlm. 1611-1612 \& hlm. 1690.

70 Ibid.

71 Qing Guangxu Zhao Zhongfa Jiaoshe Shiliao, Vol. III, 25ab (Document 76), hIm. 1932-1933.

72 Dalam bahasa Cina ditulis sebagai

73 Dalam bahasa Cina ditulis sebagai tots

${ }^{74}$ Dai Nam Thuc Luc Chinh-Bien De Tu Ky, Vol. 68, hlm. 29. Untuk kupasan tentang pengalaman Nguyen Thuat ke China sila lihat Chen Chinghe, (annotated \& ed.) Wang Jin Riji (Diary of Nguyen Thuat toward Tianjin), Hong Kong: Zhong wen da xue chu ban she, 1980, hlm. 6.

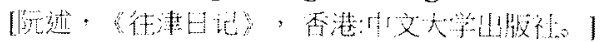

75 Shao Xunzheng, Zhongfa Yuenan Guanxi Shimo (A Complete Account of China-French Relations Concerning Vietnam), Shijiazhuang: Hebei Jiaoyu

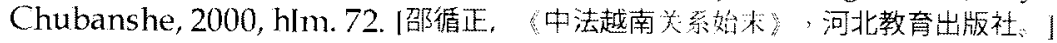

in "Surat Challeme Lacour, Foreign Minister to Bouree", 5 Mac 1883, Documents Diplomatiques Francais 1811-1914 (DDF), Vol. V (No. 5), dlm. Pei-Chih Hsieh, "Prelude to Tragedy in Vietnam: the French Annexation of Tonkin, and the Conflict with China, 1881-1885", Journal of the South Seas Society, Vol. 33, Parts $1 \& 2,1978$, hlm. 6.

7 "Surat Challeme Lacour, Foreign Minister to Tricou", 13 Mei 1883, DDF 1811-1914, Vol. V (No. 36), dlm. Ibid., hlm. 7.

is FO 421/1, Surat Zeng Jize [Marquis Tseng] kepada M. Barthelemy St. Hilaire", 24 September 1881". Diplomatic Corresponde (15 Mac 1874-13 Nov. 1883).

70 Henri Cordier, Histoire Des Relations de la Chine Avec les Puissantes Occidentals, Vol. 2 dlm. E.V.G. Kiernan, British Diplomacy in China, 1880 to 1885, hlm. 88 .

80 Dalam misi tersebut, Zeng Jize telah berjaya mengembalikan sempadan China-Rusia sepanjang $200 \mathrm{li}$ dan keluasan $400 \mathrm{li}$. Kejay aan misi rundingan 
tersebut telah menaikkan nama beliau di kalangan pihak istana China. Untuk kupasan lanjut tentang krisis China-Rusia yang melibatkan wilayah Ili, di Rusia, sila lihat "Chapter 4: Tseng's Mission to St. Petersburg", E. V. G. Kiernan, British Diplomacy in China, 1880 to 1885, hIm. 58-72.

81 Zeng Jize, Zeng lize Yiji, him. 191.

82 Hosea Ballou Morse, The Intenational Relations of the Chinese Empire, London: Longmans Green, 1910, hlm. 348.

83 Dalam soal penyerangan terhadap Hanoi contohnya, $M$. de Freycinet terus berdolak-dalik terhadap pertanyaan Zeng Jize. Pada mulanya $\mathrm{M}$. de Freycinet berkata kononnya Perancis tidak berniat untuk menawan wilayah utara Vietnam. Sila lihat $F O 421 / 1$, Surat Zeng Jize kepada $M$. De Freycinet, 6 Mei 1882 \& FO 421/1, Surat M. de Freycinet kepada Zeng lize, 31 Mei 1882 dan juga Zeng Jize, Zeng Jize Yiji, hIm. 200.

84 Selepas Maharaja Tu Duc meninggal dunia pada 16 Jun 1883. Takhta Vietnam silih berganti oleh Maharaja Duc Duc (1883 - tiga hari), Maharaja Hiep Hoa (1883 -enam bulan) dan Maharaja Kien Phuc (1883-1884).

85 Guo Tingyi dan Wang Yujun, (ed.) Zlongfa Yuenan Jiaoshe Dang, Vol. II, hlm. 1282.

86 Ibid.

87 "Usul Chen Qitai, Censor di Henan kepada Maharaja Guangxu melalui Tang Yangeng", 29 September, 1883, dim. Qing Guangxu Zhiv Zhongfa jiaoshe Shiliao, Vol. 7, him. 15.

88 FO 421/1, Surat Consul Hughes kepada Grosvenor", (Inclosure No.37), 30 Mei 1883.

89 "Usul Chen Baosheng dan Zhang Peilun kepada Maharaja Guangxu", 1 Jun 1883, dlm. Oing Guangxu Zhao Zhongfa Jiaoshe Shiliao, Vol. 2, hlm.

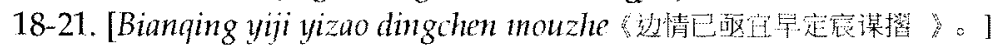

9o FO 421/1, Surat Plunkett kepada Earl Graville, (No. 4), 3 Ogos 1883.

91 Zeng Jize, Zeng Jize Yiji, hlm. 199.

92 "Surat Freycinet kepada de Saint-Vallier, duta Perancis di Jerman", 7 Julai, $1880 \mathrm{dlm}$. DDF 1811-1914, Vol. III (No. 197), dlm. Pei-Chih Hsieh, "Prelude to Tragedy in Vietnam: the French Annexation of Tonkin, and the Conflict with China, 1881-1885", hlm. 5.

93 Xu Yanxu ialah Leftenan Gubenor di Guangxi. Kemudian beliau telah dinaik pangkat menjadi Gabenor di Guangxi.

94 Tang Tong ialah Leftenan Gabenor di Yunnan. Kemudian beliau telah dinaikkan pangkat menjadi Gabenor di Yunnan.

o5 Guo Zhenduo \& Zhang Xiaomei, (eds.) Yuenan Tongshi (General History of Vietnam), Beijing: Renming daxue chubanshe, 2000, hIm. 624.

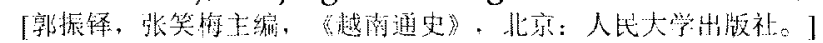

96 "Arahan Junji Chu (Council of State) kepada Liu Zhangyou", 14 Ogos 1882 dlm. Qingdezong Shilu (Veritable Record of the Emperor of Guangxu), Vo.

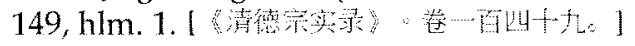

4) Untuk kupasan lebih lanjut tentang usaha-usaha China melalui pendekatan ketenteraan yang lebih agresif dan peranan Pasukan Bendera Hitam dalam Perang China-Perancis 1884-1885, sila lihat Ku Boon Dar, 
"Hubungan China-Vietnam, 1802-1885," Tesis Sarjana, Jabatan Sejarah, Fakulti Sastera dan Sosial Sains, Universiti Malaya, 2005. 